\title{
Prevention of neural tube defects in an urban health district
}

\author{
D WATSON, ${ }^{1} \mathrm{M}$ POW, ${ }^{1}$ A ELLAM, ${ }^{2}$ AND K COSTELOE ${ }^{3}$
}

From the Department of Clinical Biochemistry, ${ }^{1}$ King Edward VII Hospital, Windsor, Department of Community Medicine, ${ }^{2}$ St Leonards Road Clinic, Windsor, and Department of Paediatrics, ${ }^{3}$ Wexham Park Hospital, Slough, Berkshire, UK

SUMMARY An evaluation of voluntary prenatal screening for neural tube defects with serum alphafetoprotein (s-AFP) is presented. During a three year period, there were 52 fetuses with neural lesions. Of 46 mothers who bore a fetus with an open neural lesion, 25 were detected, of whom 23 agreed to the termination of their pregnancies. An unscreened group of 2331 mothers (17\% of all deliveries) produced 14 fetuses with neural tube defects, an incidence of 6.0 per 1000 , 1.8 times the incidence $(3.3$ per 1000$)$ in the screened group. Pitfalls occuring in the assessment of hyper-alphafetoproteinaemia included inaccurate gestational dating and allowance for excessive body weight. The results of a robost AFP-NTD screening programme supported in selected cases by ultrasonar visualisation of the spine argue for its continuance in this district.

A study of notifications of malformations of the central nervous system together with specialist reports in 1979 led the Department of Health and Social Security Working Group to conclude that $80 \%$ of cases of open spina bifida would be detected by an efficient programme, ${ }^{1}$ and the Windsor area of the East Berkshire district contributed to this first report of the United Kingdom Collaborative Study on maternal serum alphafetoprotein (s-AFP) screening. ${ }^{2}$ The present study began in March 1979 and arose from the need to examine critically the effectiveness of our screening programme in practice.

\section{Patients and methods}

The East Berkshire Health District provides maternity services for a population of 370000 . From March 1979 to March 1982 all pregnant women presenting before 19 weeks' gestation were offered screening for neural tube defects through maternal serum alphafetoprotein (s-AFP); $83 \%$ had maternal $\mathrm{s}$-AFP concentrations determined. Of the remaining $17 \%$ comprising two groups of roughly equal numbers, half presented too late to be screened and the remainder presented early but failed to reattend for screening at 16-18 weeks. Rather fewer than 100 women each year refused the test. Most patients were monitored by a system of shared care. Patients with raised s-AFP concentrations were investigated by ultrasonar scanning to exclude multiple pregnancy, to identify incorrect gestational dating, and to identify babies with anencephaly. In the absence of any cause shown by ultrasound, amniocentesis was offered and carried out either locally or at the regional unit.

We ascertained the outcome of all pregnancies in East Berkshire that were at 16 weeks' gestation between 7 March 1979 and 6 March 1982. The notes of patients with raised s-AFP or who delivered babies with neural tube defects were examined with respect to timing of screening investigations, antenatal history, maternal race and weight, and precise description of fetal pathology.

S-AFP REPRODUCIBILITY

Precision calculated from repeated duplicate s-AFP estimation $^{3}$ shows acceptable stability with coefficients of variation between $3 \%$ and $7 \%$. When a specimen with a raised s-AFP was found, the assay was repeated in the next batch, usually three days later. In no case did the results differ from the mean by more than $5 \%$. A repeat determination was made after an interval of 7-14 days on 22 volunteers. The mean rise for the 22 patients was $10 \mathrm{KIU} / 1$ per 10 days: in only two cases was no increase detected after seven days. Twice in the three year period a low s-AFP did appear to follow a raised concentration found less than a week earlier. On both occasions this 
was due to wrong patient identification, so a repeat sample after a positive screening provides a necessary check.

\section{NON-FETOPLACENTAL FACTORS AND THE S-AFP CONCENTRATION}

When a raised s-AFP in the second trimester was followed by a normal birth, a retrospective examination of the antenatal records failed to implicate any particular drug or unusual activity, though such factors cannot be rigorously excluded. There was no statistically significant difference between s-AFP measurements made in white and Asian patients, neither did the time of day that the sample was taken have any effect on the concentration.

\section{WEIGHT}

In one antenatal clinic maternal weight at the time of booking was recorded. Mean body weight for 800 mothers was $60 \cdot 5 \mathrm{~kg}(\mathrm{SD}=10 \cdot 9)$. At $16-18$ weeks' gestation, the mean s-AFP concentration (KIU/1) of 102 low weight patients (under $50 \mathrm{~kg}$ ) was $40 \cdot 1$, $\mathrm{SD}=19 \cdot 0$, whereas that of 148 high weight patients (over $71 \mathrm{~kg}$ ) was $30 \cdot 9, \mathrm{SD}=15 \cdot 5$. These concentrations were significantly different $(\mathrm{p}<0.001)$.

CRITICAL LEVELS OF S-AFP AND LIQUOR-AFP We used the criteria in table 1 for determining whether serum or liquor concentrations of AFP were raised.

\section{Results}

Of the 13906 pregnancies delivered, 11575 (83\%) were screened at $16-18$ weeks by s-AFP testing. There were 52 fetuses with neural tube defects (3.7 per 1000), of which 38 were in the screened group (3.3 per 1000$)$ and 14 in the unscreened group $(6.0$ per 1000), giving a raised prevalence 1.8 times that in the screened group.

WOMEN WITH RAISED SERUM ALPHAFETOPROTEIN

There were 188 women with inappropriately raised s-AFB, 25 of whom (13\%) had a fetus with a neural tube defect. Of the 163 without a defective fetus, 28 had underestimated the gestational age as estimated by the uterine size and the ultrasonic biparietal diameter measurements, and later confirmed by date of delivery and gestational assessment of the baby. All 28 had normal singleton livebirths (13 had had amniocentesis.)

There were 35 pregnancies with raised s-AFP confirmed by ultrasound to be twins but in the outcome one of these was a discordant anencephalic fetus.

A further 44 pregnancies (21\% of all raised AFPs) resulted in a defective fetus or infant: there were 32 second trimester spontaneous abortions about the time of the test and three other second trimester losses due to known causes; four were stillborn, all with severe intrauterine growth retardation; and five were liveborn, two of whom were neonatal deaths, two suffered intrauterine intraventricular haemorrhage, and one was microcephalic.

The remaining 56 delivered normal healthy full term singleton infants; of these patients, 47 had had amniocentesis as a result of the finding of raised s-AFP. Table 2 shows the pattern by year and by use of amniocentesis.

FETUSES WITH NEURAL TUBE DEFECTS There were 52 fetuses with neural tube defects; 17

Table 1 Serum AFP (KIU/l) and liquor AFP (mg/l)

\begin{tabular}{|c|c|c|c|}
\hline \multirow[b]{2}{*}{$\begin{array}{l}\text { Gestation } \\
\text { (weeks) }\end{array}$} & \multirow{2}{*}{$\begin{array}{l}\text { Serum } \\
\begin{array}{l}\text { Median } \\
\text { value }\end{array}\end{array}$} & \multirow[b]{2}{*}{$\begin{array}{l}\text { Action limit } \\
\text { value }(2 \cdot 8 M)\end{array}$} & \multirow[t]{2}{*}{ Amniotic fluid } \\
\hline & & & \\
\hline $16-17$ & 32 & 90 & $6-14$ \\
\hline $17-18$ & 36 & 101 & $6-12$ \\
\hline $18-19$ & 41 & 115 & $8-13$ \\
\hline $19-20$ & - & - & $4-11$ \\
\hline
\end{tabular}

Table 2 Outcome of 188 patients with "raised" s-AFP (1.6\% of 11575 pregnancies screened). (Numbers in parentheses are those who submitted to amniocentesis)

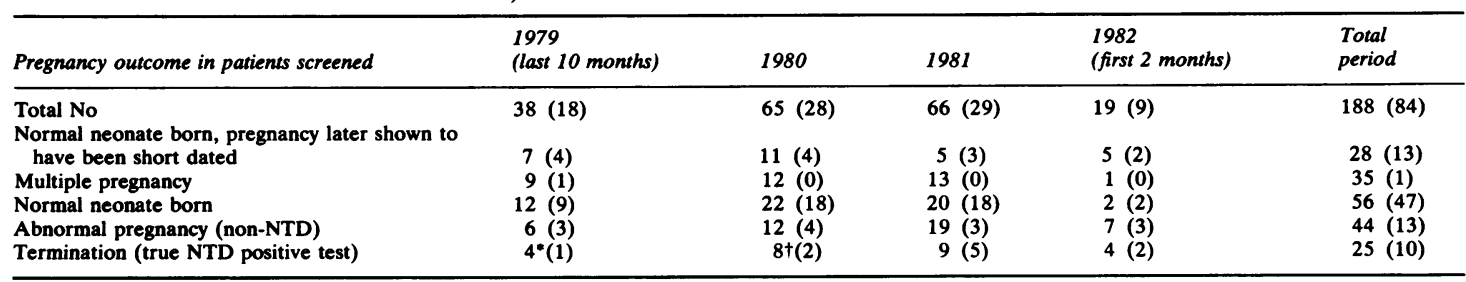

*Includes one anencephalic accompanied by normal twin.

tIncludes one refused. 
anencephalics, 30 meningomyeloceles, and five encephaloceles. Six were closed defects, one mother refused the test, two failed to attend, and 11 had booked too late. Of the 32 cases that might have been detected, seven were false negatives, two refused amniocentesis, one was diagnosed as twins, and 22 were detected and terminated (table 3 ).

\section{TWIN PREGNANCIES}

There were 127 twin pregnancies (9 per 1000) of which $35(28 \%)$ gave a raised s-AFP for the appropriate week of gestation. One of these had one fetus with anencephaly.

\section{ABSENT S-AFP}

There were 85 women in whose serum the presence of AFP could not be established with certainty-28 were less advanced in pregnancy than reported, 19 were not pregnant, and 32 subsequently spontaneously absorted. The outcome of the remaining six is not known.
OUTCOME OF FETUSES WITH NEURAL TUBE DEFECTS

Of the 52 fetuses with neural tube defects, 22 were terminated as a result of the programme, one aborted spontaneously, 10 were stillborn, and 18 were liveborn. Of the liveborn, eight are known to be dead and 10 are alive. Table 4 shows the screening result, course, and present state of the survivors.

\section{Discussion}

The success of a screening programme for neural tube defects, assuming acceptability and improved outcome, depends on the proportion of pregnant women presenting and the test specificity and sensitivity. The latter depends critically on precise AFP analysis and accurate gestational dating.

S-A F P A S SAY

Reports in Europe ${ }^{1}$ and in America ${ }^{4}$ recommended assays to be restricted to "certified" high volume

Table 3 Outcome of test in 52 fetuses with neural tube defects

\begin{tabular}{|c|c|c|c|}
\hline & Anencephalic & Meningomyelocele & Encephalocele \\
\hline Total No of cases & 17 & 30 & 5 \\
\hline Untestable cases: & & & \\
\hline Closed lesion & 1 & 3 & 2 \\
\hline Refused test & - & 1 & - \\
\hline Failed to attend & 1 & - & 1 \\
\hline Booked too late & 4 & 7 & - \\
\hline Detectable cases: & 11 & 19 & 2 \\
\hline Refused amniocentesis & - & 2 & - \\
\hline NTD twin accompanied by normal twin & 1 & - & - \\
\hline False negative & 2 & 5 & - \\
\hline Detected and terminated & 8 & 12 & 2 \\
\hline
\end{tabular}

Table 4 Surviving infants with spina bifida

\begin{tabular}{|c|c|c|c|}
\hline Patient & Maternal s-AFP & $\begin{array}{l}\text { Date of } \\
\text { birth }\end{array}$ & Course and present status \\
\hline 1 & $\begin{array}{l}\text { Mother booked too } \\
\text { late (BTL) }\end{array}$ & Oct 79 & Surgical repair. Club feet, necessitating calipers. "Doing extremely well" \\
\hline 2 & $\begin{array}{l}\text { False negative due } \\
\text { to overestimated } \\
\text { gestation }\end{array}$ & Dec 79 & $\begin{array}{l}\text { Has shunt in situ with antisyphonic device sewn in. Epileptic. Gross motor neurological deficit. } \\
\text { Viral respiratory tract infection. }\end{array}$ \\
\hline 3 & BTL & Jan 80 & $\begin{array}{l}\text { Physical milestones normal. No deficit detected with regard to bladder and bowel function and speech } \\
\text { development }\end{array}$ \\
\hline 4 & BTL & Apr 80 & Surgical repair. Now normal, no problems \\
\hline 5 & Negative (closed lesion) & Oct 80 & Growth satisfactory. No serious neurological deficit \\
\hline 6 & $\begin{array}{l}\text { Did not attend } \\
\text { for s-AFP }\end{array}$ & Dec 80 & Ventricular abdominal shunt. Good progress. No neurological deficit \\
\hline 7 & $\begin{array}{l}\text { False negative due } \\
\text { to overestimated } \\
\text { gestation }\end{array}$ & Apr 81 & Surgical repair. Confirmed meningeal sac. Normal development. No neurological deficit \\
\hline 8 & BTL & Jan 81 & Surgical repair. Growth satisfactory. No serious neurological deficit \\
\hline 9 & Refused s-AFP & Jan 82 & Hydrocephalic. Severely deformed legs; both ankles fixed with equinus varus deformity \\
\hline 10 & $\begin{array}{l}\text { Positive, but } \\
\text { refused ToP }\end{array}$ & Mar 82 & Surgical repair. Wounds healed. Apparent normal development \\
\hline
\end{tabular}


laboratories, and the need for quality control has previously been highlighted by our laboratory when results of analyses of four AFP standards were compared in four different laboratories. ${ }^{5}$ Analytical error has to be sufficiently low to give confidence in deciding whether a particular s-AFP concentration indicates inappropriate hyperalphafetoproteinaemia or not. In contrast to experience elsewhere, which suggested that a normal second s-AFP might follow after a few days a falsely raised s-AFP in $17-33 \%$ of the abnormal levels originally found (Working group on screening for NTD 1979, table 2D), ${ }^{1}$ our assay showed in almost all cases a rising level of $0.8 \mathrm{KIU} / \mathrm{ml}$ a day.

Retrospective examination of the NTD patients' data for s-AFP level, gestational age, body weight, and race shows that a 16-week cut off s-AFP raised to $96 \mathrm{KIU} / 1(3.0 \times$ median) would have resulted in missing two more neural lesions. On the other hand, action does need to be taken at a lower cut off point for the grossly overweight patient. While these data were being examined, Haddow et al showed a relationship between body weight and the s-AFP in the second trimester of pregnancy. ${ }^{\boldsymbol{B}}$ We can confirm this inverse correlation, which is sufficiently weak to be taken into clinical account only when the 16-week pregnant woman weighs $72 \mathrm{~kg}$ or more and when her s-AFP at the time exceeds $77 \mathrm{KIU} / 1$ - that is, $2.4 \times$ median. A general lowering of the action limit to this level would of course be inadvisable, bringing unnecessary worry to a larger group-in fact, more than double the number of normal pregnant women having raised s-AFP.

GESTATIONAL DATING

In pregnancies where the gestational age is overestimated the false negative results will go unrecognised, and it has been suggested that this factor may account for some of the cases (about 20\% of all cases of open spina bifida) that are currently missed by s-AFP screening. ${ }^{7}$ Regrettably this problem of overestimated gestational age giving rise to apparent normal s-AFP values which are in fact abnormal could not be thoroughly examined in the UK Collaborative Study, since only one group reported more than $2 \%$ of pregnancies with doubtful gestational ages, although they note that the "efficiency of the AFP screening test may be affected by the accuracy with which gestational age is measured."2 The experience of the collaborative group is at variance with other studies and suggests that they are a selected and possibly unrepresentative group. In contrast, the 1970 survey of British births noted $17 \%$ of patients with uncertain gestational age $^{8}$ and more recent studies have noted discrepancies of three or more weeks between the estimated and actual periods of gestation in up to $25 \%$ of pregnancies. ${ }^{910}$ In our studies ultrasound dating has been used to reclassify raised AFP results; few studies have attempted to estimate the proportion of pregnancies where gestational age should be revised downward, bringing AFP concentrations into the range requiring further investigation although, without such revisions, a higher false negative rate is inevitable. Three of our five false negative meningomyeloceles would have been positive if the gestational age had been corrected and would have increased the detection rate for meningomyelocele from $74 \%(14 / 19)$ to $89 \%$ (17/19).

\section{NTD INCIDENCE IN THE UNSCREENED}

The high incidence of neural tube defects (6 per $1000)$ in the unscreened population suggests strong selective factors for screening and contributes to the lower than theoretical overall percentage detected. Early in the study period the incidence of neural tube defects in the unscreened population was even higher. The proportion of non-attenders has remained almost constant at about $17 \%$, however, whereas the proportion of neural tube defects in this group appears to have fallen over the three years of the programme, and we have no explanation for this at present.

RAISED S-AFP AND NON-NTD PATHOLOGY Hyper s-alphafetoproteinaemia is a poor indicator of multiple pregnancy, and in only one in four cases did news of a twin pregnancy arise after ultrasonography initiated by a raised s-AFP. The value of a raised s-AFP in fields other than neural tube defects however, should not be discounted. As already detailed, several serious abnormalities were heralded by inappropriate s-alphafetoproteinaemia. Other second trimester losses included one renal agenesis, one chromosome translocation, one premature rupture of membranes associated with an intrauterine contraceptive device, and one extrauterine pregnancy. Outside the period studied we have encountered one exomphalos and one infantile polycystic kidney disease. Thirty patients suffered miscarriages or termination due to intrauterine death shortly after the test had indicated a raised s-AFP, presumably the result of a non-viable fetus. Two others, however, underwent amniocenteses after inappropriately raised s-AFP and normal ultrasonar scan and aborted within four weeks of the amniocentesis. Since these losses were closest of all in time to the amniocentesis (among the 84 who underwent this procedure) and no discernable cause was established, we are unable to say that amniocentesis was not implicated in the fetal death. 
EFFECTIVENESS OF THE SCREENING PROGRAMME

The major problem of our programme is that of the cases of open spina bifida that are not being detected. Half of these have arisen in the unscreened population. Of those screened, although gross overweight accounted for one and wrong gestational age for three false negatives, there remain three unexplained false negatives. Seven had hoped for protection against the birth of an affected child and one of the two mothers with surviving infants with spina bifida understandably resents the missed abnormality. Assuming that analytical and clinical skills are maintained and ultrasonar expertise developed, however, we may reasonably expect the test failure rate to decrease. Permanently on the debit side we have both the accidental abortion or perinatal morbidity resulting from the amniocentesis and the cost of the various professional staff needed.

On the credit side, we believe that we have already substantially reduced the number of severely disabled children born in this district. Of the 10 surviving infants with spina bifida arising from the period surveyed, eight have had surgical repairs and have no residual major neurological handicap, while two children have gross handicap including hydrocephalus, paralysis of the legs, and absent bowel and bladder tone. We can, however, identify another 14 pregnancies that have been terminated for the same abnormality (12 meningomyeloceles, 2 occipito encephaloceles, table 3 ). No normal fetus was terminated, and all terminations of pregnancy were for true pathology. We also believe that in some instances when patients had no identifiable cause for their inappropriate hyper-alphafetoproteinaemia, the abnormal laboratory finding led to improved management and care. Finally, although probably fortuitous, it is noteworthy that no patient screened for neural tube defects and found normal during 1981 or 1982 (almost half the period surveyed) subsequently produced an abnormal fetus.

In conclusion, we recommend that: (1) Every endeavour should be made to screen the entire pregnant population, so that any mothers left unscreened are those exercising an informed choice; more publicity in GPs' surgeries and antenatal clinics may be necessary. (2) Reliable and reproducible assays for termining AFP in serum and amniotic fluid need $i v$ be continually maintained and quality assessment monitored. (3) An action limit of $2.8 \times$ median for 16,17 , or 18 weeks will be satisfactory, provided that gestational age is correct \pm 5 days, and maternal weight is under $72 \mathrm{~kg}$. (4) Nursing staff at antenatal clinics or practices must have sufficient time to communicate freely with laboratory staff, to explain the screening procedure, and to contact and, where neccessary, counsel recalled patients. (5) Amniocentesis should be restricted to those with apparent inappropriate hyper-alphafetoproteinaemia for whom expert ultrasonar visualisation is not available.

We acknowledge the excellent collaboration of Sister Holland, Heatherwood Hospital, Ascot, Mrs J M Steel and Sister McGuire, Canadian Red Cross Memorial Hospital, Taplow, and of our obstetric consultant colleagues, Messrs T D Anderson, J Hughes, S C Simmonds, and N R A Trickey whose patients were studied. We thank Mrs P Jackson and Mr G Willing for their help with laboratory data assessment, and Mrs F Hughes, who in 1978 set up and standardised the current AFP assay.

Requests for reprints to: The Secretary, Department of Clinical Biochemistry, Wexham Park Hospital, Slough, Berkshire SL2 4HL.

\section{References}

${ }^{1}$ Working Group on the Screening for Neural Tube Defects. Report. London: Department of Health \& Social Security. 1979. (Black report.)

${ }^{2}$ First Report of UK Collaborative Study on $\alpha$-foetoprotein in relation to ENTD. Maternal serum $\alpha$-foetoprotein measurement in antenatal screening for anencephaly and spina bifida in early pregnancy. Lancet 1977; ii: 1323-32.

${ }^{3}$ Khadempour MH, Laing I, Gowenlock AH. An optimised radioimmunoassay for maternal serum $\alpha$ foetoprotein using polyethylene glycol. Ann Clin. Biochem 1978; 15: 213-20.

4 American College of Obstetrics and Gynecologists and American Academy of Pediatrics. AFP task force report. Washington: US Food \& Drug Administration, 1979.

${ }^{5}$ Watson D, Pow M. Diagnostic reagents for alphafetoprotein. Lancet 1976; i: 1015.

${ }^{6}$ Haddow JE, Kloza EM, Knight GJ, Smith DE. Relation between maternal weight and serum alphafetoprotein concentration during the second trimester. Clin Chem 1981; 27: 133-4.

${ }^{7}$ Harris R. Maternal serum alphafetoprotein in pregnancy and the prevention of birth defects. Br Med J 1980; 280: 1199-202.

* Chamberlain R, ed. British births. Vol 1. London: Heinemann, 1970.

${ }^{9}$ Roberts CJ, Hibbard BM, Evans DR, et al. Precision in estimating gestational age and its influence on sensitivity of alphafetoprotein screening. Br Med J 1979; i: 981-3.

${ }^{10}$ Grace HJ, Gray R, Conradie JD. Prenatal detection of neural tube defects by maternal serum alphafetoprotein assay. $S$ Afr Med J 1981; 60: 319-24. 